\title{
EXPLORING THE RADICALIZATION PIPELINE ON YOUTUBE
}

\author{
Amanda R. Champion, Research Associate and Partner - Canadian \\ Association for Security and Intelligence Studies Vancouver, Canada
}

Disclaimer: This briefing note contains the encapsulation of views presented by the speaker and does not exclusively represent the views of the Canadian Association for Security and Intelligence Studies.

\section{Key Events}

On September 16, 2021, Amanda Champion presented Exploring the Radicalization Pipeline on YouTube at the 2021 CASIS Vancouver Defence and Security Advisory Network Workshop. Champion discussed incel and misogynistic radicalization on YouTube in order to uncover and explore its effect on the broader network of extremist groups.

\section{Nature of Discussion}

Extremists and radicalized groups have taken advantage of the Internet to attract members, gather support, and establish an online presence to further distribute radicalized and extremist ideologies. In response, analysts use numerous online risk assessments tools to identify the potential for online radicalization of individuals. Ms. Champion's research focused on the presence of incel and misogynist groups on YouTube. In mapping out the network of recommended incel and misogynist videos, Ms. Champion has found that exploring the pipeline of radicalized incel groups can "identify central, influential or popular video content within the broader community and this gives researchers great insight to infer shared beliefs or perspectives, especially when paired with additional information." To map out the potential connections of these YouTube videos, her study uses the Social Network Analysis and Network Overview Discovery (SNA) \& Exploration Pro (NodelXL Pro). For the purpose of this study, data extracted from this model was used to examine online incel and incel related communities and the quantity of contact within these groups.

\section{Background}

Ms. Champion commenced her presentation with the context surrounding the investigation of radicalization on YouTube. She demonstrated how the Internet can facilitate passive and active consumption of extremist messaging, propaganda, and other radicalizing materials. For example, the Internet has been 
used extensively by terrorist groups such as Al-Qaeda and ISIS to radicalize individuals. Her presentation explored the indirect and direct methods deployed by terrorists, extremists, and lone actors which feed online propaganda to targeted audiences, namely supporters, opponents, and the global community. As the study of the online radicalization pipeline uses the incel group of a study focus, Champion offered a thorough background on incel groups to explain the effect of the multiple networks of online incel communities and their increasing contribution to offline violent attacks (using several recent high profile incelrelated attacks (Elliot Rodger (2014), Chris Harper-Mercer (2015), Alek Minassian (2018), etc.as case studies). Incels have been recognized as a growing online radicalized group that continue to incite acts of lone-actor mass violence.

The incel movement beliefs that the natural order of heterosexual monogamous coupling was put out of order during the 1960's feminism movement intended to raise awareness about women's rights and bodily autonomy. Ms. Champion introduces a common term of the incel community called "Black Pill ideology" which is used to describe the pessimist view of the inevitable subjection to one's place in the social hierarchy. Although not required, many incels adopt the Black Pill ideology. The Black Pill ideological sphere includes elements such as biological determinism, fatalism, defeatism, pessimism, and nihilism with feminism and women as the main culprits. A pictorial interpretation taken from a publication written by Zimmerman et al. (2018) explains that typical incel rationale asserts that women are not to be treated as equal members of the society and should not exercise the freedom to decline men they do not want. The incel ideology also believes that feminism must be overthrown as a result of depriving men of sexual pleasures, emotional intimacy and affection by female counterparts.

To map out the algorithmic network of incel-related videos on YouTube, Ms. Champion began an in-depth research study using SNA adopted from "Analyzing Social Media Networks with NodeXL" (Hansen et al., 2011) using typical incel keywords as search terms. The study's main objective was to figure out the types of incel-related community clusters that exist on YouTube; to identify the central and most influential incel-related videos in the YouTube network that bridge the communities; and to explore the viewing path that YouTube's algorithm takes viewers on, in other words, the radicalization pipeline. The data set is composed of 903 YouTube videos with 1,039 unique edges (An edge is a connection between elements of networks (vertices). The unique edges count are the number of multiple connections that are only counted once between vertices). NodeXL Pro produced a visual graph of the incel-related YouTube video recommendation 
network that plotted central videos, groups, and themes. Groups were created using the Clauset-Newman-Moore (an algorithm which primary function is to separate groups when there are numerous connections within a distinct intragroup and only a few intergroup connections between outside communities) that maximizes modularity (Clauset et al., 2004). To take the study a step further, a manual content analysis was conducted on 10 random videos in each group to better uncover the course to more radicalized information and propose connections between distinct groups.

Although these findings are tentative, this study has shown that the radicalization pipeline for incel-related content likely exists, influential videos with more followers have the potential to disseminate radicalized ideas, and some YouTube channels link innocuous videos to radicalized ideology.

\section{Key Points of Discussion}

- Radicalization activities on YouTube facilitate passive and active consumption of extremist messaging, propaganda.

- Extremists and radicalized groups take advantage of the largely unrestricted and widespread platform YouTube to attract new members, gather support, and establish a sense of online presence to further distribute radicalized and extremist ideologies and messages.

- "Misogynist terrorism" has been a growing area of extremist activity, as this group has been observed to incite acts of mass violence.

- A radicalization pipeline for incel-related content likely exists and indicates that videos with a high number of followers and views have the potential to disseminate extremist ideas virally and normalize the dehumanizing views of women held by many incels.

\section{Critical Thinking Question}

- Is there a divide within the interaction between incel communities on YouTube and other social media platforms?

\section{Key Terms}

Black Pill Ideology: The black pill ideology is adopted by incel members who believe their inferior facial / body features has subjected them to the abject reality of constant rejection of sexual and emotional connections with women. As a result, they are rooted to the bottom rung of the society. Incel members who uphold this ideology have a very pessimistic view of their circumstance as they 
believe the abject reality of constant scorn and rejection by women (sexually and emotionally) and society in general is absolutely resolute (Manne, 2018).

Incel: Involuntary celibates, or "incels," are people who define themselves by their inability to have sexual intercourse and romantic relationships (Preston et al., 2021)

Misogynist Terrorism: Misogynist terrorism is the violent act that forms part of the strategy of vindicating the "political objective of policing and enforcing women's subordination and to uphold male dominance" (Diaz \& Valji 2019; Schwenkenbecher 2012).

\section{Further Readings}

Alternative influence: Broadcasting the reactionary right on YouTube (n.d.) by Rebecca Lewis.

https://datasociety.net/wpcontent/uploads/2018/09/DS_Alternative_Influence.pdf

Exploring the "radicalization pipeline" on YouTube. In R. Corrado, G. Wössner, \& A. Merari (Eds.), Terrorism risk assessment instruments (pp. 359374). NATO Science for Peace and Security Series - E: Human and Societal Dynamics, 152. IOS Press Ebooks (2021) by Amanda Champion \& Richard Frank

National strategy on countering radicalization to violence. Government of Canada (2018) by Public Safety Canada https://www.publicsafety.gc.ca/cnt/rsrcs/pblctns/ntnl-strtg-cntrng-rdclztnvlnc/ntnl-strtg-cntrng-rdclztn-vlnc-en.pdf 


\section{References}

Beauchamp, Z. (2019, April 23). Our incel problem. Vox. https://www.vox.com/the-highlight/2019/4/16/18287446/inceldefinition-reddit

Clauset, A., Newman, M. E. J., \& Moore, C. (2004). Finding community structure in very large networks. Physical Review E, 70(6),

Diaz, P. C., \& Valji, N. (2019). Symbiosis of misogyny and violent extremism: New understandings and policy implications. Journal of International Affairs, 72(2), 37-56. https://www.jstor.org/stable/26760831

Hansen, D., Shneiderman, B., Smith, M., \& Himelboim, I. (2011). Analyzing social media networks with Node XL: Insights from a connected world. Elsevier.

Manne, K. (2018). Down girl: The logic of misogyny. Oxford University Press.

Preston, K., Halpin, M., \& Maguire, F. (2021). The black pill: New technology and the male supremacy of involuntarily celibate men. Men and Masculinities. https://doi.org/10.1177/1097184X211017954

Schwenkenbecher, A. (2012). Terrorism: A philosophical enquiry. Palgrave Macmillan.

Zimmerman, S., Ryan, L., \& Duriesmith, D. (2018). Recognizing the violent extremist ideology of 'Incels.' Georgetown Institute for Women, Peace and Security. https://giwps.georgetown.edu/resource/recognizing-theviolent-extremist-ideology-of-incels/

\section{cc)}

EY NC ND This work is licensed under a Creative Commons Attribution-NonCommercial-NoDerivatives 4.0 International License.

(C) (AMANDA CHAMPION, 2021)

Published by the Journal of Intelligence, Conflict, and Warfare and Simon Fraser University

Available from: https://jicw.org/ 